\title{
Visual Cortex Development in the Ferret. I. Genesis and Migration of Visual Cortical Neurons
}

\author{
Cheryl A. Jackson, Jean D. Peduzzi, and T. L. Hickey \\ Department of Physiological Optics, School of Optometry/The Medical Center, University of Alabama at Birmingham, \\ Birmingham, Alabama 35294
}

\begin{abstract}
The production of ferret visual cortical neurons was studied using ${ }^{3} \mathrm{H}$-thymidine autoradiography. The genesis of cortical neurons begins on or slightly before embryonic day 20 (E20) of the $41 \mathrm{~d}$ gestational period, continues postnatally until 2 weeks after birth (P14), and follows an inside-out radial gradient with neurons for the deeper cortical layers being generated before those for the superficial layers. Layer I neurons are generated both early (E20-E30) and late (P1-P14) in the period of cortical neurogenesis and, thus, provide at least a partial exception to the inside-out gradient of cortical neurogenesis. Tangential gradients of cortical neurogenesis extend across areas 17 and 18 in both the anterior-to-posterior and lateral-to-medial directions. Neither of these gradients bears a meaningful relationship to the cortical representation of the visual field. Most infragranular and granular layer neurons are generated prenatally, while most supragranular layer neurons are produced postnatally. Neurons destined for a given layer are produced over a period of several days, and the neurons generated on any given day contribute to the formation of $\mathbf{2}$ or more cortical layers. In general, prenatally generated neurons complete their migration in 1 week or less, while most postnatally generated neurons require approximately 2 weeks to complete their migration.
\end{abstract}

All mammalian species studied so far demonstrate an insideout spatiotemporal gradient of cortical neurogenesis. Such gradients are most distinct in primates, where the period of cortical neurogenesis is protracted (Rakic, 1974). However, the high cost and limited supply of primates, coupled with their long gestational period, severely restrict the number of animals that can be studied. Animals with very short gestational periods, like the rodent, are inexpensive and readily available, but cortical neurogenesis occurs at such a rapid pace that gradients of cortical neuron production are much less distinct (e.g., Angevine and Sidman, 1961). In contrast, the ferret's relativcly short gestational period (41-42 days), coupled with a protracted ( 35 days) period of cortical neurogenesis, affords distinct spatiotemporal gradients of neuronal production and an extended period of postnatal cortical neurogenesis. In this paper, we define the pe-

\footnotetext{
Received May 26, 1988; revised Aug. 8, 1988; accepted Aug. 29, 1988.

This work was supported by NIH Grants EY01338, EY03039 (CORE), and RR05807. These data, along with a more complete description of visual cortical cytoarchitectural development, were submitted in partial fulfillment of the requirements for the Ph.D. degree from The University of Alabama at Birmingham (1986). We thank Mrs. Pam Kontzen for her expert assistance.

Correspondence should be addressed to Dr. Terry L. Hickey at the above address.

Copyright (C) 1989 Society for Neuroscience $0270-6474 / 89 / 041242-12 \$ 02.00 / 0$
}

riod of neuronal production and the final adult location of neurons generated at different times during the period of cortical neurogenesis in the ferret and provide information about the timecourse of neuronal migration.

\section{Materials and Methods}

Animals

All animals were offspring of time-bred ferrets obtained from Marshall Farms, New York. The ferret has an average gestational period of 41 $\pm 1 \mathrm{~d}$. The date of breeding has been designated E0; the date of birth, Pl.

Ferrets injected with ${ }^{3} \mathrm{H}$-thymidine and then sacrificed as adults. For experiments concerned with the final location of cortical neurons generated at different times during cortical development, pulse injections of ${ }^{3} \mathrm{H}$-thymidine were delivered to developing ferret kits on a single embryonic or postnatal day between $\mathrm{E} 20$ and P16. The numbers of animals injected at each prenatal age were: E20 (1 kit), E22 (3), E24 (3), E26 (3), E27 (5), E29 (4), E30 (2), E31 (2), E32 (2), E33 (2), E34 (2), E35 (3), E36 (4), E38 (4), and E40 (2). The numbers of animals injected at each postnatal age were: P1 (4 kits), P2 (3), P4 (4), P5 (1), P6 (1), P8 (6), P10 (3), P12 (4), P14 (3), and P16 (2). All of these ferrets were sacrificed at 2-4 months after birth, when cortical cytoarchitecture is indistinguishable from that seen in 2-year-old ferrets. The animals were deeply anesthetized by an overdose of ketamine hydrochloride and killed by vascular perfusion. After a rinse with physiological saline or with 0.1 м phosphate buffer ( $\mathrm{pH} 7.4$ ), the tissue was fixed with $10 \%$ formol saline or with $2 \%$ paraformaldehyde and $2 \%$ glutaraldehyde in $0.1 \mathrm{M}$ phosphate buffer.

Ferrets injected with ${ }^{3} \mathrm{H}$ thymidine and then killed during development. Tritiated thymidine injections were made on either E24, E30, E36, P1, $\mathbf{P} 4$, or P8; radioactively labeled kits were then killed at one of the following days: E30, E36, P1, P4, P8, P14, P21-P22, P28-P33, or P42$\mathrm{P} 44$ (see Table 1). It was necessary to modify the perfusion procedure used for late embryonic and neonatal animals. Neonatal animals and some embryos (E36 and E38) were anesthetized with ether and perfused at a lower pressure. Embryos killed very early in gestation (E22-E30) were fixed by immersion after opening the cranial cavity.

\section{${ }^{3} \mathrm{H}$-thymidine injection procedures}

Prenatal injections (E20-E38) of $250 \mu \mathrm{Ci}$ of ${ }^{3} \mathrm{H}$-thymidine [NET-027Z thymidine (Methyl- ${ }^{3} \mathrm{H}$ ), $50-80 \mathrm{Ci} / \mathrm{mmol}$; or ICN-24060 thymidine (Methyl- $\left.{ }^{3} \mathrm{H}\right), 60-90 \mathrm{Ci} / \mathrm{mmol}$, in sterile aqueous solution] were made through the uterine wall into the allantoic cavity of each conceptus (Hickey et al., 1983). For postnatal injections, $500 \mu \mathrm{Ci}$ of ${ }^{3} \mathrm{H}$-thymidine was administered intraperitoneally into each ferret kit at ages ranging from E40 (early delivery induced by 20 units of oxytocin) to P16. The pulse width of ${ }^{3} \mathrm{H}$-thymidine availability following intraperitoneal injections in mice $(30-60 \mathrm{~min})$ has been shown to be similar to the brief pulse width following intravenous administration of radioactive DNA precursors (Blenkinsopp, 1968).

\section{Histological procedures}

All brains were stored in the appropriate fixative for at least $24 \mathrm{hr}$ before processing. Pieces of tissue containing the caudal part of the cortex and surrounding areas were blocked from brains older than P22, while youn- 
ger brains were processed whole. Brains were dehydrated for $48-72 \mathrm{hr}$ in a 1:1 mixture of methanol and Cellosolve (ethylene glycol monomethyl ether). Embedding procedures were performed at $38^{\circ} \mathrm{C}$ using polyester wax (Sidman et al., 1961). Processing times were adjusted according to the age of the brain being processed.

Wax sections were cut at $6-15 \mu \mathrm{m}$ with a rotary microtome. The adult brains were cut in a number of different planes, but the horizontal plane was the most useful for defining cortical layers and localizing the border between areas 17 and 18 . Brains from young animals were cut in the horizontal plane to facilitate analysis of the rotation of the visual cortical areas that takes place during development. A 1-in-5 series of sections was mounted on gelatin-subbed slides, dipped in a $50 \%$ solution of Kodak NTB-2 nuclear track emulsion, and exposed for 4-6 weeks at $4^{\circ} \mathrm{C}$. The slides were developed in Kodak D-19 developer, rinsed in tap water, and fixed with Kodak Rapid Fix. All sections were stained with thionin, dehydrated, cleared in Histoclear, and coverslipped.

\section{Data collection}

The terminology of Otsuka and Hassler (1962) is used throughout this study. In the upper or supragranular layers (layers I-III) of the ferret's visual cortex, clear subdivisions are apparent only between the cellsparse plexiform layer I and layer II. As a result, we did not divide layers II and III in any of our analyses. The boundaries of area 17 were determined in the Nissl-stained sections by the presence of a cell-sparse layer V. While area 17 could be identified by P14, the exact boundaries of visual cortex were difficult to discern in younger animals. For this reason, analyses of neuronal migration were confined to an area at the posterior pole of the developing cortex, lateral to the hippocampus and caudal to the lateral sulcus. Since there is a substantial overlap in the windows of neurogenesis for areas 17 and 18 (see Results), the possibility that the sampling area contained some neurons destined to form area 18 in the adult does not alter the conclusions obtained in this study.

Ferrets injected with ${ }^{3} \mathrm{H}$-thymidine and then killed as adults. The final location of heavily labeled neurons was marked using an $X-Y$ plotter electronically coupled to the stage of a microscope. Neurons were identified in the Nissl-stained sections by their large, pale, round, or oval nuclei with one or more dark nucleoli and by the presence of Nissl substance within their cytoplasm. Glial cells were identified by a smaller nucleus with scattered heterochromatin and a thin rim of cytoplasm. Heavily labeled neurons were defined as those with $50-100 \%$ of the maximum number of silver grains found over the nuclei of neurons in that animal. The pattern of heavily laheled neurons obtained after qualitative estimation of label density, however, was indistinguishable from that obtained using the more quantitative method.

To analyze the spatiotemporal gradients of cortical neurogenesis, plots of the location of heavily labeled neurons were made at 3 horizontal and coronal levels in 2 adult ferrets from each injection age studied. Qualitative comparisons of these plots across injection dates revealed radial spatiotemporal gradients of neurogenesis across the cortical layers and tangential spatiotemporal gradients of neurogenesis across the entire cortical mantle in adult animals. The presence of these spatiotemporal gradients was quantitatively confirmed by calculating the median radial position of neurons generated on a particular day. The superficial (pia) to deep (white matter) positions of all heavily labeled neurons within a $1000 \mu \mathrm{m}$ radial strip of cortex were entered via a Talos digitizing tablet into a PDP $11 / 34$ computer. The position of the sampling strip was chosen so that the curvatures of the pial surface and the white matter were at a minimum. Extremely curved regions of cortex were avoided since our observations suggest a slightly greater laminar spread of labeled neurons at the top of a gyrus. The region chosen, a relatively flat part of the visual cortex at the area $17 / 18$ border, also eliminated any variability introduced by tangential gradients (see Results). Laminar boundaries were superimposed upon the computer output to obtain the laminar locations of the $0,25 \mathrm{th}, 50 \mathrm{th}, 75 \mathrm{th}$, and $100 \mathrm{th}$ percentiles, with the 0 percentile corresponding to the location of the heavily labeled neuron nearest to the cortical surface, the 100th percentile corresponding to the location of the heavily labeled neuron farthest from the cortical surface and the 50th percentile corresponding to the median location of all heavily labeled neurons in the sample. In all between-animal comparisons, measurements were taken at the same visual field location and normalized to a cortical width typical of that area.

Ferrets injected with ${ }^{3} \mathrm{H}$-thymidine and then killed during development. For studies of neuronal migration, plots were performed on horizontally sectioned tissue taken from near the caudal pole of the cortex. Comparisons across a series of animals injected on the same embryonic day

\begin{tabular}{|c|c|c|c|c|c|c|c|c|c|}
\hline \multirow{2}{*}{$\begin{array}{l}\text { Age at } \\
\text { injec- } \\
\text { tion }\end{array}$} & \multicolumn{9}{|c|}{ Age at time killed } \\
\hline & E30 & E36 & $\mathrm{P} 1$ & $\mathbf{P 4}$ & P8 & $\mathrm{P} 14$ & $\begin{array}{l}\text { P21- } \\
\text { P22 }\end{array}$ & $\begin{array}{l}\text { P28- } \\
\text { P33 }\end{array}$ & $\begin{array}{l}\text { P42- } \\
\text { P44 } \\
\end{array}$ \\
\hline E24 & 5 & 5 & 6 & 4 & 6 & 4 & 2 & 1 & 2 \\
\hline E30 & & 5 & 6 & 5 & 4 & 4 & 2 & 5 & 2 \\
\hline E36 & & & 5 & 3 & 4 & 4 & 1 & 3 & 1 \\
\hline P1 & & & 3 & 4 & 2 & 3 & 1 & 2 & 1 \\
\hline P4 & & & & 3 & 2 & 2 & 2 & 2 & 2 \\
\hline P8 & & & & & 4 & 3 & 2 & 3 & 2 \\
\hline Total & 5 & 10 & 20 & 19 & 22 & 20 & 10 & 16 & 10 \\
\hline
\end{tabular}

and sacrificed at different developmental stages were analyzed for changes in the positions of labeled cells over time. Comparisons between each series of injection days were analyzed for differences in the laminar position achieved by the labeled cells within the developing cortex, for differences in the time necessary to reach the adult cortical position, and for qualitative changes in the density of labeled cells throughout development. It must be stressed that the undifferentiated appearance of the majority of the cells within the cortex at embryonic and early neonatal stages makes it difficult to distinguish neurons from glia and therefore many of the heavily labeled cells plotted at early ages may actually be glial cells in the adult cortex.

\section{Results}

\section{Spatiotemporal gradients of visual cortical neurogenesis}

Spatiotemporal gradients of neuronal production are seen in both the radial dimension (across the cortical layers) and in the tangential dimension (across the different cortical areas or across different parts of the visual cortex). In general, neurons labeled after ${ }^{3} \mathrm{H}$-thymidine injections late in the period of cortical neurogenesis lie superficial to those labeled after early injections, yielding an inside-to-outside radial sequence of cortical nerve cell production. In addition, rostral-to-caudal and lateral-tomedial tangential gradients of neuronal production are also apparent.

E24 and earlier. Small numbers of heavily labeled neurons are evident in area 17 in animals injected with ${ }^{3} \mathrm{H}$-thymidine on either E20 or E22. The majority of the neurons generated on these $2 \mathrm{~d}$ are interstitial neurons located within the white matter below area 17 , although a few heavily labeled neurons are also found in layer I. The final adult locations of neurons generated $2 \mathrm{~d}$ later, on E24, are shown in Figure 1. To illustrate the relative density and locations within the cortex of neurons generated on E24, drawings showing the location of heavily labeled neurons at 3 horizontal and coronal levels throughout the visual cortex are provided. This figure displays data obtained from 2 animals. The laminar positions of heavily labeled neurons in a radial strip of cortex located at the $17 / 18$ border and near the cortical representation of the area centralis are shown in the drawing contained in the rectangular box near the middle of the figure. Heavily labeled neurons are found in the white matter, layer VI, and layer I. Although not shown here in their entirety, similar plots were made for animals injected on E30, $\mathrm{E} 35, \mathrm{P} 1, \mathrm{P} 4$, and P8. The laminar positions of the heavily labeled neurons at each of these ages are shown in Figure 2.

$E 26$ through $E 29$. Injections of ${ }^{3} \mathrm{H}$-thymidine on E26 and E27 yield heavily labeled neurons located throughout the lower half of layer VI. An occasional heavily labeled neuron is seen in layer 


\section{CORONAL}

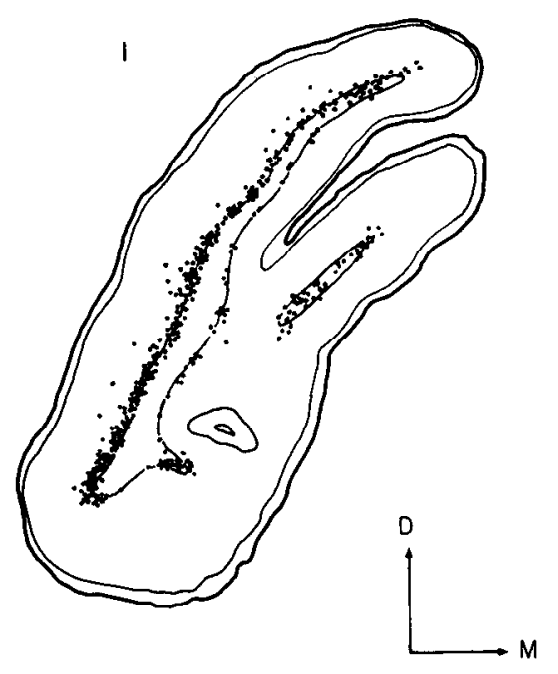

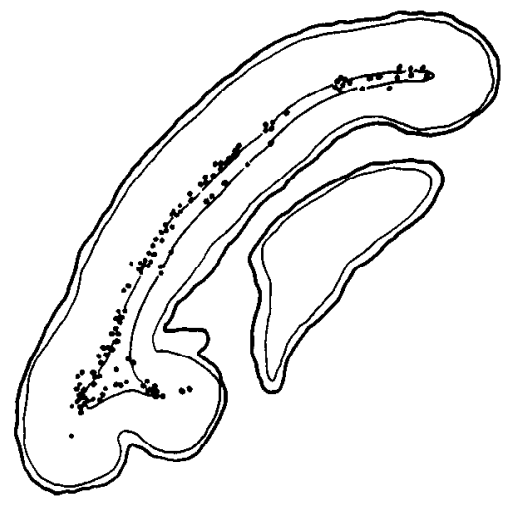

3

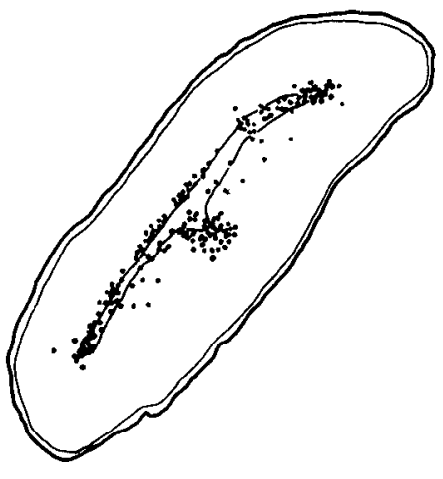

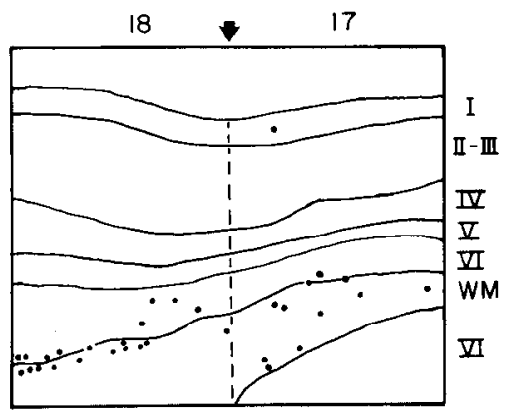

\section{HORIZONTAL}
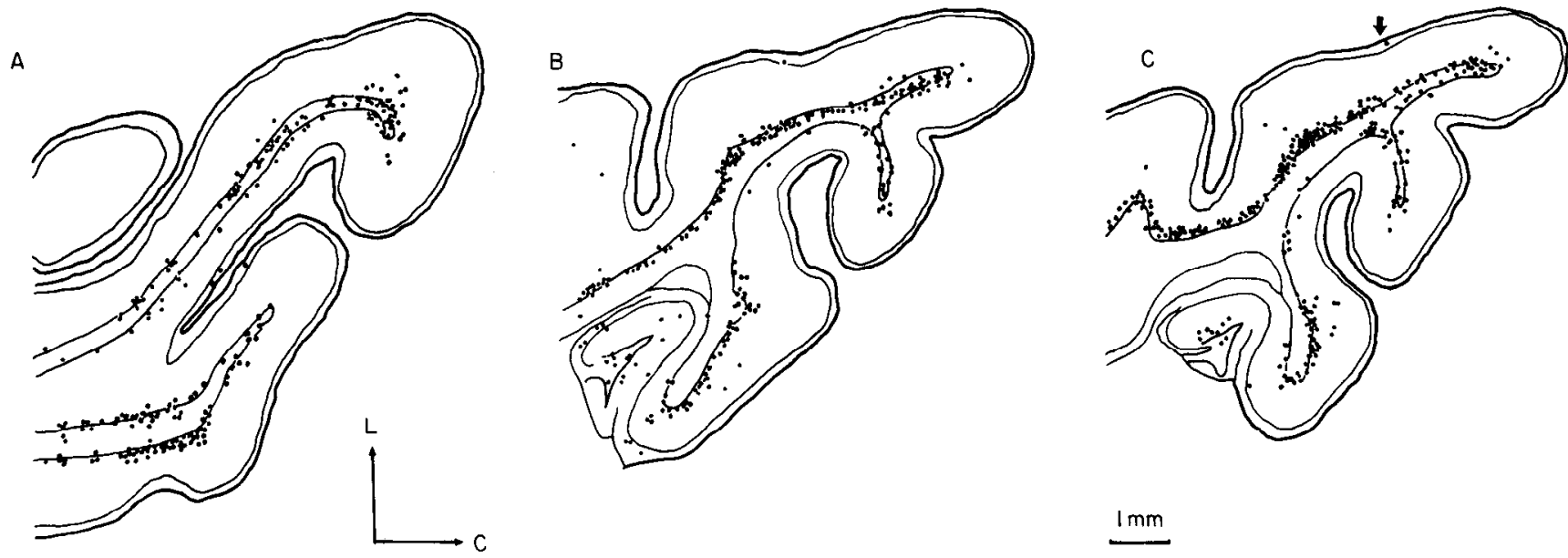

$1 \mathrm{~mm}$

Figure 1. Camcra lucida drawings of coronal (top) and horizontal (bottom) sections through the visual cortex in adult ferrets injected with ${ }^{3} \mathrm{H}-$ thymidine on embryonic day 24 (E24). The coronal levels 1-3 correspond to the anterior-to-posterior levels indicated in the line drawing of the ferret cortex shown on the left. The horizontal levels $A, B$, and $C$ correspond to the dorsal-to-ventral levels indicated on the cortical outline. Each heavily labeled neuron is represented by a black dot. Scale bar, $1.0 \mathrm{~mm}$. A higher-power view of the laminar position of the heavily labeled neurons at the $17 / 18$ border is shown in the right middle panel. This sample was taken from a region marked by the black arrow in the most ventral horizontal section (level $C$ ). 

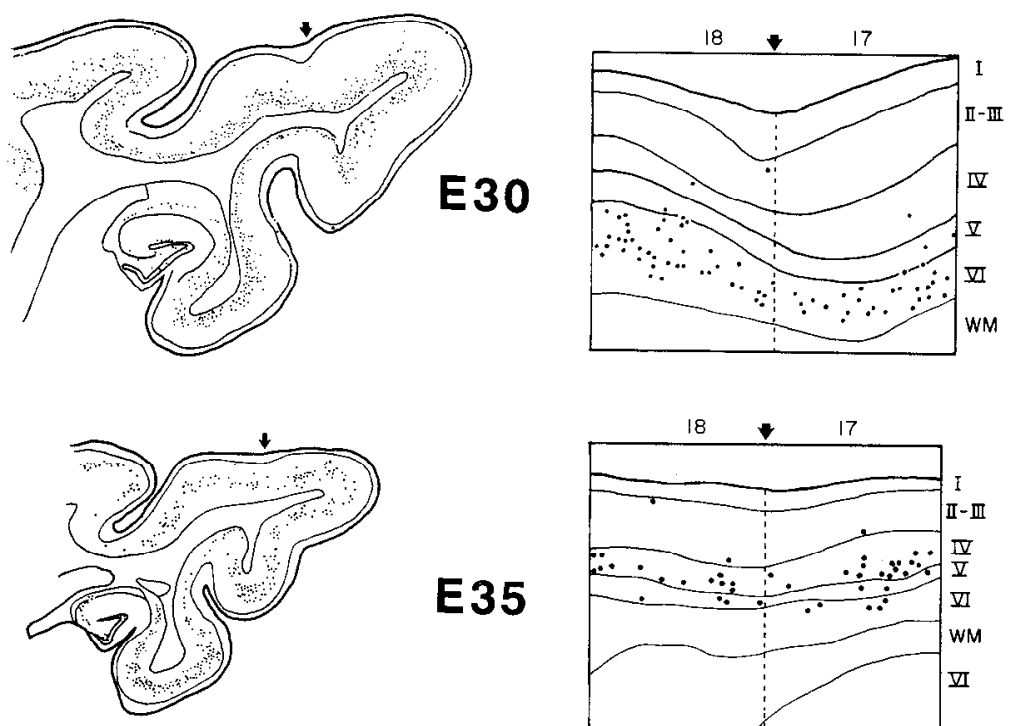

E35
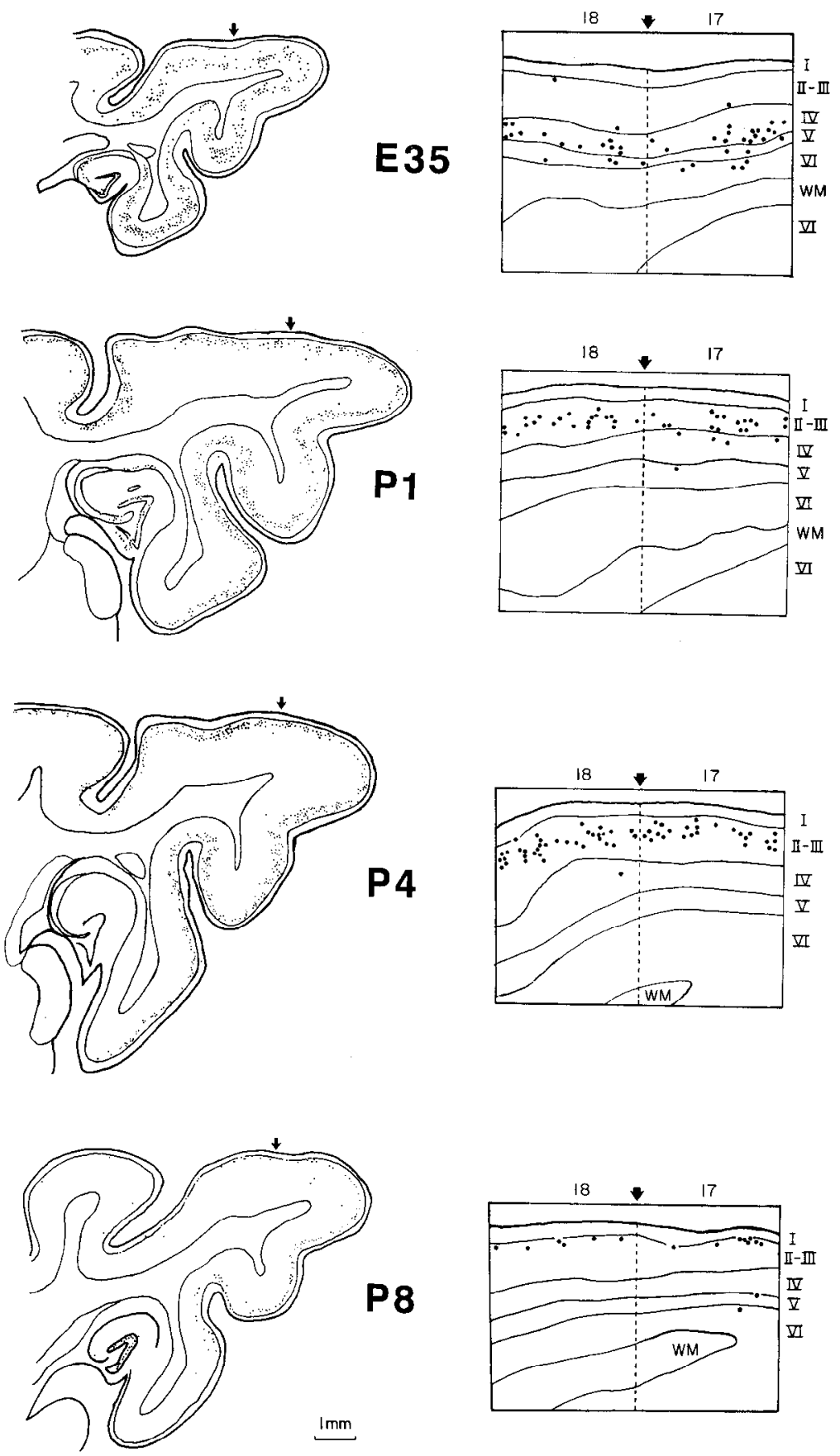

$\mathrm{V}$ at more anterior levels or at the crest of a gyrus. Heavily labeled interstitial neurons are still apparent in ferrets injected on E26 and E27 but are not evident in animals injected on E29, indicating that the production of interstitial neurons extends for
Figure 2. Left, Camera lucida drawings of the most ventral (level C) horizontal sections through the visual cortices of adult ferrets injected with ${ }^{3}$ II-thymidine on one of the following days: E30, E35, P1, P4, or P8. Right, Higher-power views of the laminar positions of the heavily labeled neurons at the $17 / 18$ border in each of the sections shown at left. All other conventions as in Figure 1. an $8 \mathrm{~d}$ period beginning on E20. Heavily labeled layer I neurons are seen throughout this period.

E30 through E34. The vast majority of neurons produced on E30 are located in layer VI, with a smaller number being located 
in layer V and, rarely, in layer IV (Fig. 2). Labeled neurons located anteriorly tend to lie superficial to those located more posteriorly. Unfortunately, the large number of neurons generated on E30 obscures the presence of any lateral-to-medial gradient of neuronal production that might exist at this point in time. Heavily labeled neurons in layer I are still seen after injections on E30 but are only rarely seen in this material after later prenatal injections. These findings indicate that the production of most prenatally generated layer I neurons extends from on or before E20 until E30 and overlaps in time with the production of interstitial neurons and deep layer VI neurons. Heavily labeled neurons in area 18 tend to lie superficial to those in area 17, although there is substantial overlap in the laminar positions of the labeled neurons seen in the 2 areas.

The final adult positions of neurons generated on E31, E32, and E33 are similar to those seen in the E30 material, with the exception that more labeled neurons are found within layer $\mathrm{V}$ in the later-injected animals. By E34, the majority of heavily labeled neurons are found in layer $\mathrm{V}$ or at the bottom of layer IV. Those heavily labeled neurons found in layer VI are located immediately adjacent to layer $\mathrm{V}$.

$E 35$ through $E 40$. The large number of neurons generated on E35 prevents an analysis of the tangential gradients of neuronal production. Neurons generated on E35 are scattered across a number of adjacent cortical layers. A few labeled neurons are found at the top of layer VI, a larger number are found within layer V, and the majority are found within layer IV (Fig. 2). Most of the labeled neurons in layer IV are located in the lower half of the layer, although a few are located at the border between layers III and IV. While an injection of ${ }^{3} \mathrm{H}$-thymidine on the following day, E36, yields similar results, later prenatal injections do not label any neurons in layer VI. The production of layer VI neurons has drawn to a close by E36, and approximately 2 weeks has been required to produce all the neurons in both sublaminae of this layer.

Injections of ${ }^{3} \mathrm{H}$-thymidine in the last few days of gestation (E38 and E40) label a large number of neurons throughout layer IV and an occasional large pyramidal neuron at the layer III/ IV border. While a few heavily labeled neurons are found within layer $V$ after an E38 injection, no heavily labeled layer $V$ neurons are seen after an E40 injection. The production of layer $V$ neurons, therefore, extends for an $12 \mathrm{~d}$ period from E27 to E38 and, thus, is complete by birth.

P1 through P2. Large numbers of heavily labeled neurons are seen in animals injected with ${ }^{3} \mathrm{H}$-thymidine on the day of birth (P1), indicating that the production of ferret visual cortical neurons extends into the postnatal period. A few neurons generated on $\mathrm{P} 1$ are found in the upper part of layer IV, while the majority are found in the lower half of layer II-III (Fig. 2). Rarely, a neuron generated on $P 1$ is found in layer $V$ or in the lower half of layer I. The density and distribution of heavily labeled neurons generated on P2 are similar to those seen following a P1 injection. No heavily labeled neurons are found in layer IV, indicating that the production of layer IV neurons, which began on E32, is completed 10 d later on P1.

P4 through P6. With few exceptions, all neurons generated on P4 are found in layer II-III of the adult ferret visual cortex (Fig. 2). An occasional small, heavily labeled neuron is also found in the lower part of layer I and in the deeper cortical layers. Relatively few heavily labeled neurons are seen anteriorly, suggesting that the production of neurons in these regions is nearing completion. Although fewer neurons are generated on the following days, P5 and P6, those that are produced are distributed in a manner similar to those seen following a P4 injection.

P8 through P14. Neurons produced on P8 are located in the most superficial portion of layer II and within layer I (Fig. 2). Labeled neurons were encountered infrequently in the deeper cortical layers. These rare late-generated deep layer neurons may represent neurons that failed to migrate to the top of the cortical plate during development. In more medial parts of the visual cortex there is a greater spread of heavily labeled neurons throughout layer II-III. An anterior-to-posterior gradient of neuronal production was also apparent.

Injections of ${ }^{3} \mathrm{H}$-thymidine on either $\mathrm{P} 10$ or P12 label small numbers of neurons at the interface between layers I and II. These neurons are often found in clumps of 4-5 labeled nerve cells with large intervening regions devoid of labeled neurons. Injections on P14 label very few neurons at the I/II border. Although a few layer I neurons are produced throughout the period from P10 to P14, the production of layer I and layer IIIII neurons is complete by $\mathrm{P} 14$, and only glial cells are produced after this time. Thus, the superficial cortical layers are generated almost entirely in the first 2 postnatal weeks. Although the total number of neurons in layer I is quite small, postnatal neuronal production of this layer also extends until 2 weeks after birth.

\section{Median position of heavily labeled neurons}

More quantitative analyses of the radial positions within the cortex of neurons generated on a single embryonic or postnatal day are summarized for areas 17 and 18 in Figure 3. Here, the relative positions of neurons generated on a given day are shown in terms of percentiles. The crosshatching marks the positions of the 0-100th percentiles and corresponds to the range of adult positions of heavily labeled neurons. Heavily labeled neurons within layer I are marked by additional crosshatching. Radial positions between the 25 th and 75 th percentiles are marked by the shaded areas. Fifty percent of the heavily labeled neurons within the strip of cortex sampled lie within this shaded area. The radial position of the 50th percentile, or median, is represented by a white arrow within the shaded area. At postnatal stages, the heavily labcled ncurons are closcly packed in the radial dimension and their median position lies in the center of the narrow shaded area.

It is clear that the production of visual cortical neurons does not take place in discrete steps in which neurons destined for each cortical layer are generated during separate, nonoverlapping periods. Rather, visual cortical neurogenesis follows a continuous, inside-out radial distribution that does not appear to be influenced by the boundaries of the cortical layers. Neurons found in 2 or more cortical layers can be generated on the same day in development, and the neurons making up a single cortical layer are generated over a period of several days. Even though there is substantial overlap in the final adult locations of neurons generated at different times, a distinct inside-out gradient does exist. For example, when the radial distribution of the central $50 \%$ of the neurons generated on a single day (represented by the shaded areas) is considered, the inside-out spatiotemporal gradient is quite apparent, primarily because the radial distribution of the central $50 \%$ of the neurons is not affected by single neurons that lie well above or below the majority of neurons generated on that day. The median radial positions, indicated by the white arrows, reveal even less overlap in the inside-tooutside gradient of neurogenesis. 
AREA 17

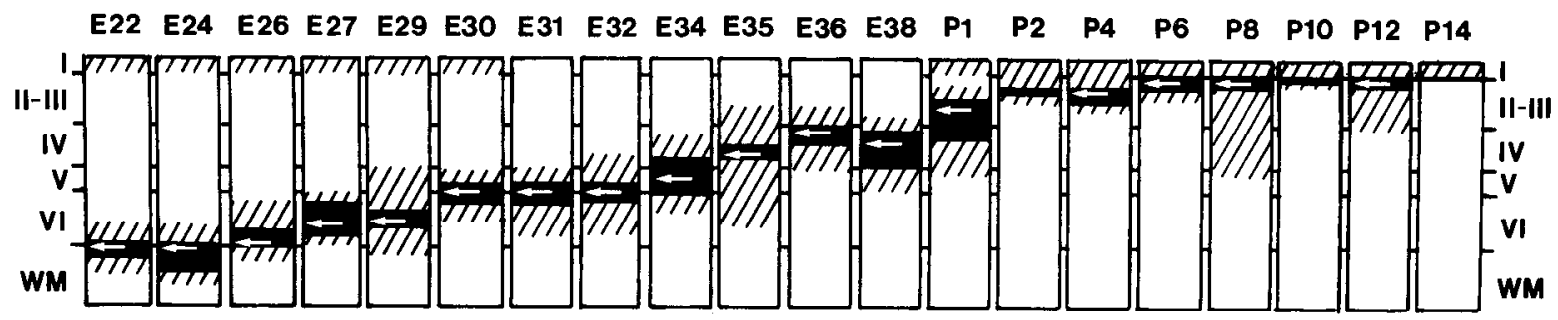

AREA 18

E22 E24 E26 E27 E29 E30 E31 E32 E34 E35 E36 E38 P1 P2 P4 P6 P8 P10 P12 P14

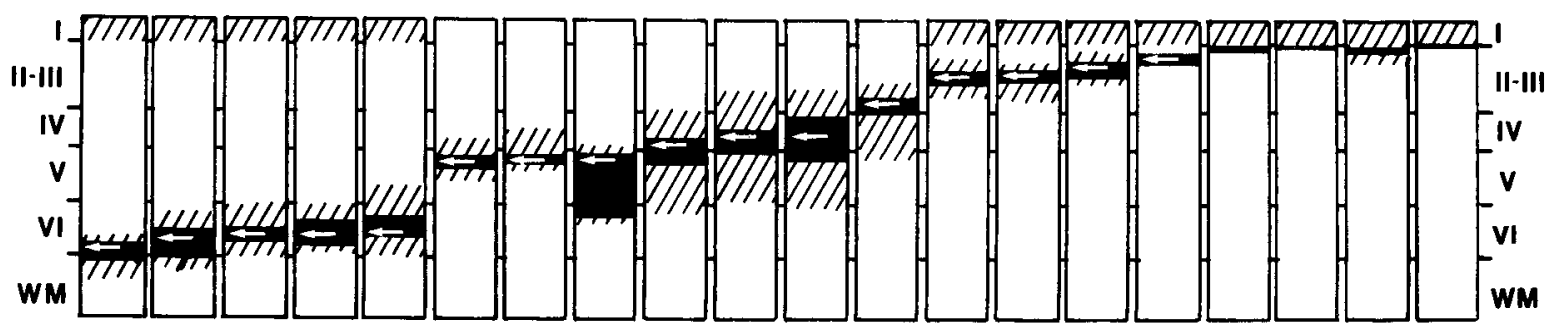

Figure 3. Quantitative analyses of the radial positions within the cortex of neurons generated on a single embryonic or postnatal day were performed by calculating the distance from the pial surface for each heavily labeled neuron in a $1000 \mu \mathrm{m}$ strip of cortex in areas 17 and 18 of the adult. The regions sampled were located near the lateral $17 / 18$ border at a horizontal level close to the representation of the area centralis. The ${ }^{3} \mathrm{H}$-thymidine injection days are listed at the top of each column, and the relative locations of the cortical layers are shown on the sides. All measurements were normalized to a cortical thickness typical of the cortex in the region sampled. In each strip through the cortex, the positions corresponding to the 0,25 th, 50 th (median), 75 th, or 100th percentiles are shown. The crosshatching corresponds to the range (0-100th percentile) of radial positions observed within the cortex in that sample. The shaded areas represent radial positions between the 25 th and 75 th percentiles. The distance from the pial surface of the 50th percentile is shown by the white arrow embedded within the shaded area. This represents the median radial position of all heavily labeled neurons generated on that day in development. Crosshatching has also been used to indicate the presence of heavily labeled neurons in layer I. However, crosshatching in layer I does not necessarily mean that such neurons were found in that particular radial strip but,
rather, that heavily labeled layer I neurons were present in animals injected on that day.

\section{Migration of cortical neurons}

Information about neuronal migration is provided in Figure 4 for ferret kits killed from E30 to P8, in Figure 5 for ferret kits killed at P14 and P21, and in Figure 6 for kits killed on P33, $\mathrm{P} 42$, or at maturity. The day of ${ }^{3} \mathrm{H}$-thymidine injection is shown at the top of each column, and the age at sacrifice is listed at the beginning of each row. Each panel represents a radial strip through a horizontal section taken near the representation of the area centralis or, in the very young brains, near the caudal pole of the telencephalon. The pial surface is at the top and the ventricular zone, or the white mattcr, lics at the bottom of each panel. The layers of the developing cortex are listed on the left. Each black dot in the panels shown in Figures 4-6 represents the location of a heavily labeled cell. It is very likely that some of the black dots shown in Figures 4 and 5 represent developing glial cells. It was not always possible to tell the difference between heavily labeled neurons and glial cells at these early stages. At the older stages shown in Figure 6, each black dot represents a heavily labeled neuron. At these stages, the neurons in all the cortical layers displayed mature, or relatively mature, cytological characteristics and the majority of glial cells displayed lower amounts of label, indicating that they had undergone repeated cell divisions after the period of ${ }^{3} \mathrm{H}$-thymidine availability.

Cells generated on E24 reside in the white matter and the deepest portions of layer VI in the adult ferret visual cortex. Examination of the column for E24 in Figure 4 reveals that at
E30, $6 \mathrm{~d}$ after injection of ${ }^{3} \mathrm{H}$-thymidine, the majority of the cells born on E24 are found among and slightly below the unlabeled cells of the cortical plate. On E36, the cells labeled on E24 are found at slightly deeper positions within the cortex. The pancls for sacrifice times P1, P4, and P8 reveal that the cells labeled by E24 injections are found in the region of the subplate zone and are subsequently displaced to deeper positions within the developing cortical wall during the first postnatal week. Note that at each survival time sampled, heavily labeled cells are found within layer I and the subplate zone.

The relative positions of the cells generated on E24 remain the same in the panels shown in Figure 5 for sacrifice ages P14 and P21. By P33, when the subplate zone is no longer apparent, neurons labeled by E24 injections are now found in the deepest parts of layer VI (layer VIb) and in the white matter. In Figure 6 , the pattern of heavily labeled neurons seen in ferrets injected on E24 and killed at a month after birth is similar to that seen in the adult, except for the changes in neuronal packing density associated with the development of the cortical neuropil. Heavily labeled neurons continue to be seen within layer I at these stages, although they are not as denscly distributed as in tissue from prenatal and early postnatal kits.

The neurons generated on E30, shown in the second column in Figures 4-6, are destined to reside in layer V and VI. Most of these neurons reach the top of the cortical plate by E36 and assume deeper positions in the cortical plate in the days that follow. The positions of cells generated on E36 are shown in the 


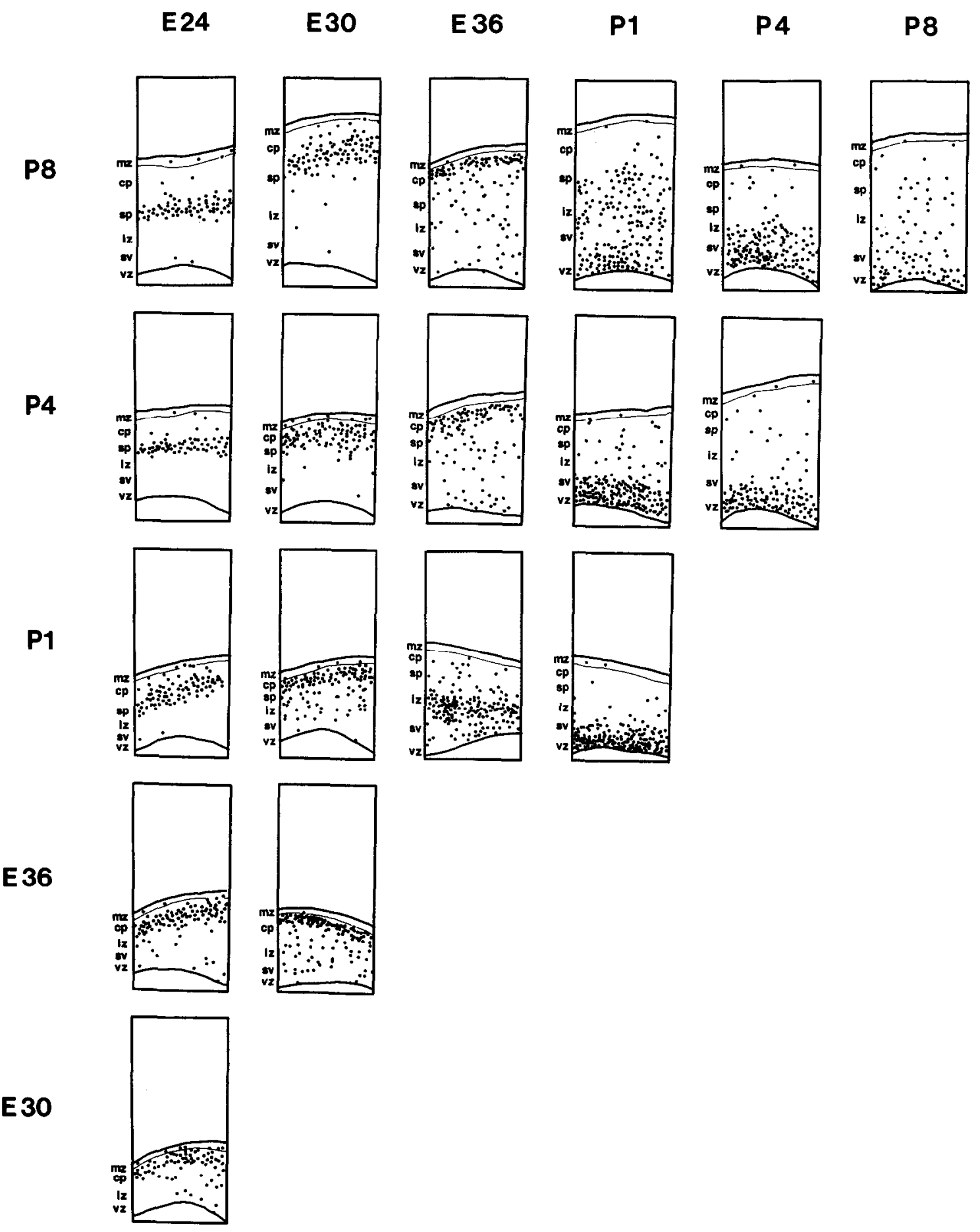

Figure 4. Each panel in this figure represents a radial strip from a horizontal section through the developing visual cortex. In each panel, the pial surface is at the top, and the ventricular zone is at the bottom. The embryonic or postnatal day of ${ }^{3} \mathrm{H}$-thymidine injection (E24-P8) is shown at the top of each column, while the age at sacrifice (E30-P8) is listed to the left of each row. Each black dot represents a heavily labeled cell. $v z$, ventricular zone; $s v$, subventricular zone; $i z$, intermediate zone; $s p$, subplate zone; $c p$, cortical plate; $m z$, marginal zone.

third column of Figures 4-6. The majority of these cells are destined to reside in layer IV. These neurons reach the top of the cortical plate between P4 and P8. Comparisons of the positions of heavily labeled cells in the columns for prenatal ${ }^{3} \mathrm{H}-$ thymidine injections in Figures 4 and 5 reveal that all prenatally generated ferret visual cortical cells are in their relative adult positions by P14. In general, the number of heavily labeled cells encountered within each sampling strip decreases with age as a function of cortical growth.

The last 3 columns in Figures 4-6 show the locations of heavily labeled cells after postnatal injections and demonstrate the same sequence of migration across the expanding cortical wall. Most of the postnatally generated neurons are destined to reside in layer II-III. The bottom panels in the columns for P1, P4, 
E 24

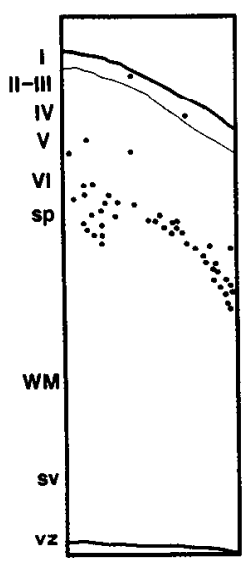

E30

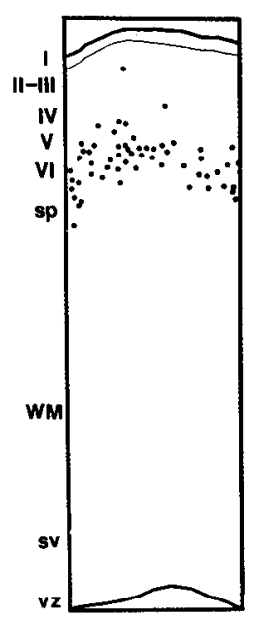

E36

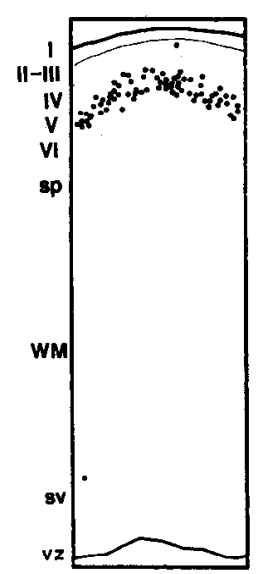

P1
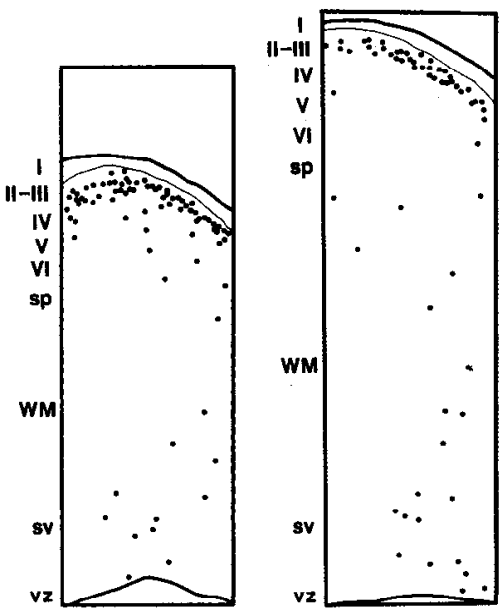
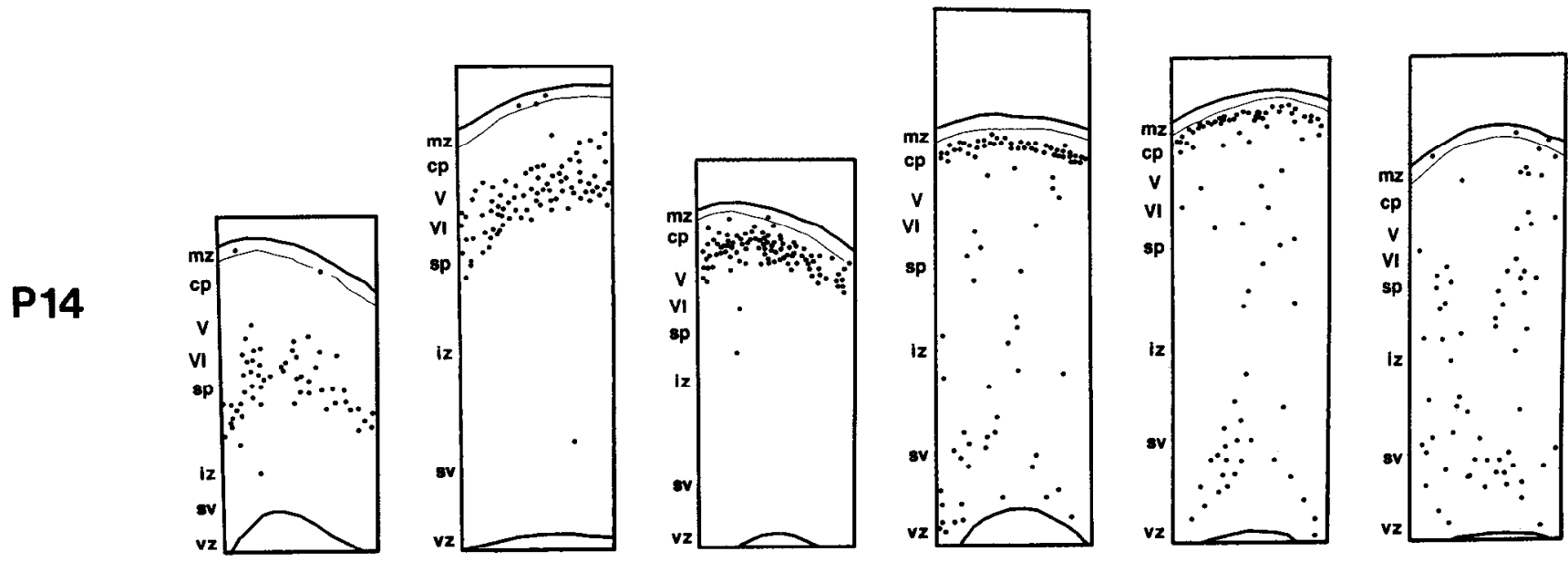

Figure 5. Each panel in this figure represents a radial strip from a horizontal section through the developing ferret visual cortex. In each panel, the pial surface is at the top, and the ventricular zone is at the bottom. The embryonic or postnatal day of ${ }^{3} \mathrm{H}$-thymidine injection (E24-P8) is shown at the top of each column, while the age at sacrifice (P14 or P22) is listed to the left of each row. Each black dot represents a heavily labeled cell. $v z$, ventricular zone; $s v$, subventricular zone; $s p$, subplate zone; $W M$, white matter; $V I$, layer VI; $V$, layer V; $I V$, layer IV; $I I-I I I$, layer II-III; $I$, layer I.

and P8 in Figure 4 show the locations of heavily labeled cells in ferret kits killed $4 \mathrm{hr}$ after intraperitoneal injections of ${ }^{3} \mathrm{H}$ thymidine. In the panels for the P1 and P4 injections, the vast majority of labeled cells are located in the ventricular and subventricular zones, with relatively more cell division taking place in the subventricular zone than seen earlier in neurogenesis. However, even after this short period, some heavily labeled cells are found higher in the developing cortical wall, in the intermediate zone and the cortical plate, and overlap in position with earlier born cells. These labeled cells may be glial cells dividing in place. A similar pattern is seen after P8 injections, although the numbers of heavily labeled cells in the ventricular and subventricular zones have decreased. Examination of the columns for postnatal injections in Figure 5 shows that in ferret kits killed on P14, most of the cells born on P1 and P4 have completed their migrations and are now in their adult positions within the superficial cortical layers. By P21, more of the postnatally generated cells, including those born on $\mathrm{P} 8$, are now found in their adult positions. A number of heavily labeled cells are still found scattered at deeper levels of the developing cortex. Examination of the panels for postnatal injections in Figure 6 shows that the laminar distribution of ferret visual cortical neurons resembles that found in the adult by P33, and the number of labeled neurons in the sampling strip through the cortex decreases with the continued growth of the cortex.

\section{Neuronal migration}

In comparison to prenatally generated neurons, many postnatally generated cells require a longer time to complete their migrations across the cxpanded cortical wall. The migratory sequence is completed in less than $6 \mathrm{~d}$ by prenatally generated neurons destined to reside in the infragranular layers, while most postnatally born neurons destined for the supragranular layers require a longer time to complete their migrations. For all injection dates sampled, the distribution of labeled neurons is similar to that seen in the adult by the end of the first postnatal 
$\begin{array}{llllll}E 24 & E 30 & E 35 / 36 & P 1 & P 4 & \text { P8 }\end{array}$

\section{ADULT}
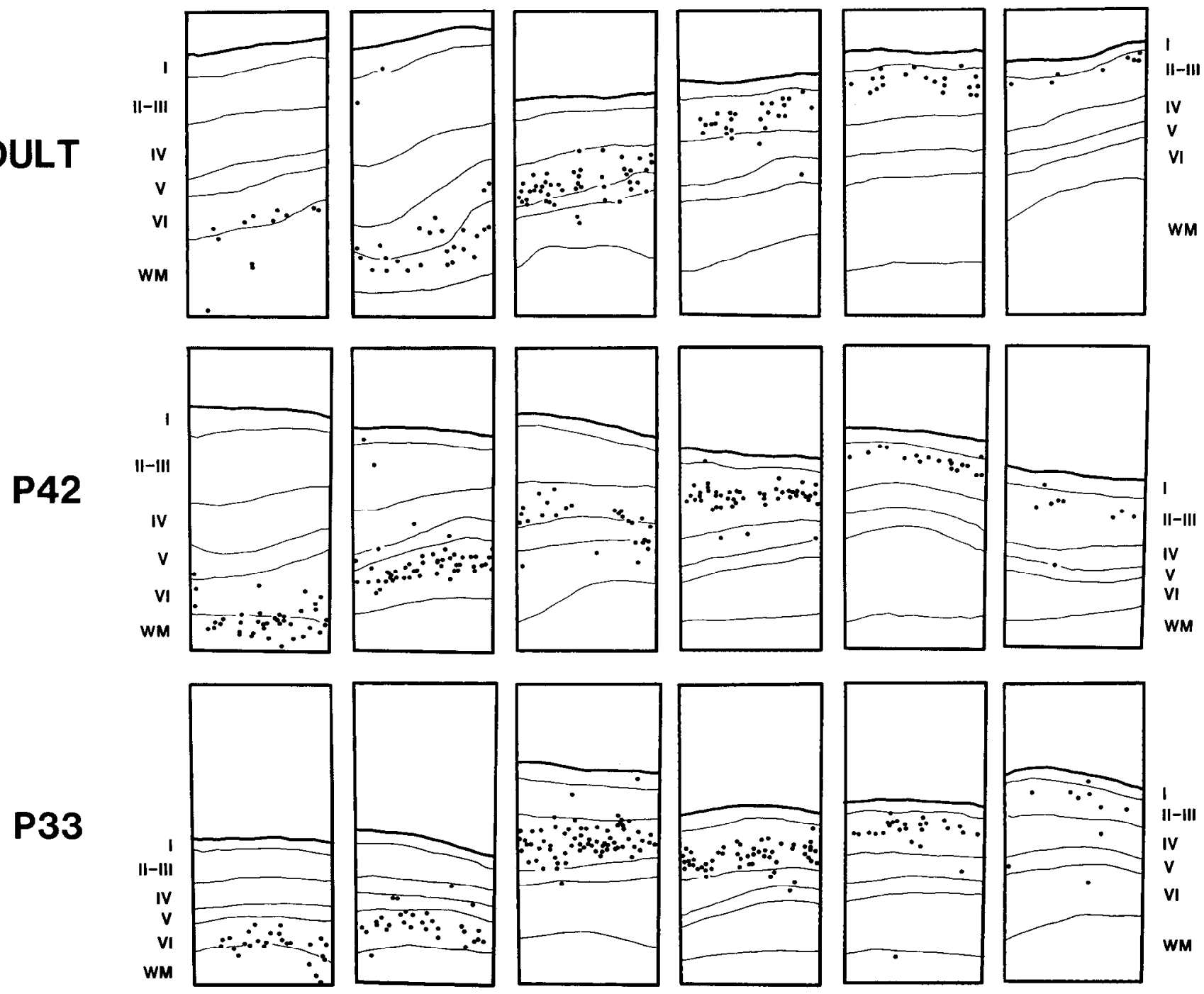

Figure 6. Each panel in this figure represents a radial strip from a horizontal section through the developing ferret visual cortex. In each panel, the pial surface is at the top, and the white matter is at the bottom. The embryonic or postnatal day of ${ }^{3} \mathrm{H}$-thymidine injection (E24-P8) is shown at the top of each column, and the age at sacrifice ( $\mathrm{P} 33$-adult) is listed to the left of each row. Each black dot represents a heavily labeled neuron. The relative positions of the cortical layers and the white matter $(W M)$ are shown at the sides of the first and last panel in each row.

month. These studies also reveal that the inside-out radial gradient is, with the exception of the early-generated neurons of layer I, established within the cortical plate from the onset of neurogenesis and that the scatter in positions of cells produced on a single day is present throughout all developmental stages studied.

\section{Glial genesis in the ferret visual cortex}

Heavily labeled glial cells were found after injections throughout the period of cortical neurogenesis. The labeled glial cells were more prevalent after postnatal injections and were most noticeable in tissue from postnatally injected ferrets that were killed $2-3$ weeks after birth. In these animals, large numbers of heavily labeled cells were encountered in the V-shaped subventricular zone extending out from the lateral ventricle. Differentiating between glial cells and neurons is difficult at these stages, and over time more neurons labeled after postnatal injections are evident in their adult positions in the superficial layers, so some of the heavily labeled subventricular cells must become neurons. The vast majority, however, probably become glial cells in the adult.

\section{Discussion}

Spatiotemporal gradients of visual cortical neurogenesis

Neurogenesis in the ferret visual cortex extends for a $35 \mathrm{~d}$ period beginning in the second half of the $41 \mathrm{~d}$ gestational period and continuing until 2 weeks after birth. Genesis of the interstitial neurons of the white matter occurs from E20 to E27, overlapping largely with the prenatal period of layer I neurogenesis (E20E30) and the production of the horizontally oriented neurons located deep in layer VI (layer VIb). Neurons destined for more superficial parts of layer VI are generated over a longer period, from E22 to E36. The production of layer V neurons extends from E27 to E38, while layer IV neurogenesis extends from E32 
to P1. Neurons in the supragranular layer II-III are first produced on E35; however, the bulk of neurogenesis for this region occurs postnatally from P1 to P14. Layer I neurons are generated both prenatally, from E20 to E30, and postnatally, from P1 to P14. Thus, the production of visual cortical neurons follows a continuous inside-out sequence in the radial dimension such that late-generated neurons lie superficial to those generated earlier. This inside-out sequence, which has been noted in a number of other species, is the most distinctive spatiotemporal gradicnt of cortical neurogenesis. Differences in the timing of cortical neuron production have been noted across species, and the relatively protracted period of cortical neurogenesis in the ferret resembles that seen in the cat (Luskin and Shatz, 1985b) and the monkey (Rakic, 1974). In general, the inside-out gradient is maintained within each cortical layer, with the majority of neurons in the lower portions of a layer generated before those located more superficially. The best example of a "withinlayer" gradient is seen in layer VI, probably because in comparison to other cortical layers the production of layer VI neurons is quite protracted. Layer VI neurons are generated for a 2-week period from E20 to E36. Similar results have been noted for layer VI in the monkey (Rakic, 1974, 1977) and hamster (Crossland and Uchwat, 1982).

Gradients of neuronal production were also noted in the anterior-to-posterior and lateral-to-medial directions, with the occipital pole being one of the last cortical areas to develop. Tangential gradients of neuronal production across the visual cortex are most apparent at the beginning and the end of the window of visual cortical neurogenesis and the most marked tangential gradient is an anterior-to-posterior gradient across the cortex as a whole. As a result, neurons in area 18 are generated slightly ahead of their counterparts in area 17. An anterior-to-posterior gradient of cortical neuronal production has also been noted in ${ }^{3} \mathrm{H}$-thymidine studies in the monkey (Rakic, 1976) and the cat (Luskin and Shatz, 1985b) and in morphometric studies of the developing ferret cortex (McSherry, 1984; McSherry and Smart, 1986). A lateral-to-medial gradient of neuronal production is also apparent within area 17 , particularly near the end of the period of cortical neurogenesis. In general, neurons generated on any given day tend to be more superficially localed in the lateral parts of the visual cortex than in the more medial regions. Furthermore, cortical neurogenesis for lateral parts of the visual cortex is nearing completion at a time when neurons are still being actively produced for more medial parts of the visual cortex. A lateral-to-medial gradient in neuronal maturation has also been mentioned by McSherry (McSherry, 1984; McSherry and Smart, 1986).

\section{Cortical neurogenesis and visual field topography}

Other ${ }^{3} \mathrm{H}$-thymidine studies have suggested a relationship between neuronal birthdate and the topographic representation of the visual field. Neurogenesis for the cat retina follows a topographic gradient along the central-to-peripheral visual field representation (Walsh and Polley, 1985). However, in the visual cortex of the cat, where the only tangential gradient found was in the anterior-to-posterior direction, neurogenesis does not follow a central-to-peripheral topographical gradient (Luskin and Shatz, 1985b).

Area 17 in the ferret is located on the dorsal, tentorial, and medial surfaces of the posterior lateral gyrus. Central visual fields are located laterally and ventrally, and the representation of the area centralis is found at the posterolateral edge of area
17. Peripheral visual fields extend onto the caudal portion of the dorsal surface of the lateral gyrus and rostrally around the tentorial surface (Guillery et al., 1985; Law et al., 1988). Retrograde transport from the dorsal lateral geniculate nucleus (dLGN) reveals that the dorsal surface of area 17 receives input from regions of the dLGN known to represent lower visual fields, while the tentorial surface receives input corresponding to upper visual fields (Guillery et al., 1985). Therefore, a lateral-to-medial gradient in the production of neurons in area 17 of the ferret would follow a central-to-peripheral visual field representation along the horizontal meridian. However, since a similar gradient is not seen along the vertical meridian representation, it would seem reasonable to conclude that the central-to-peripheral gradient of neurogenesis in the ferret cortex is only coincidental. For a similar central-to-peripheral gradient within area 18, it would be necessary for neurons in the most caudal portions of area 18 , adjacent to the vcrtical meridian representation at the $17 / 18$ border, to be generated before those located in more rostral portions of area 18 . Such a gradient is, in fact, just the opposite of the anterior-to-posterior tangential gradient of neurogenesis seen in the ferret.

\section{Layer I neurons and interstitial neurons}

Layer I neurons in the ferret are produced at both the beginning (E22-E30) and end (P1-P14) of the period of cortical neurogenesis. The larger, early-generated layer I neurons may be equivalent to the Cajal-Retzius cells, which are generally believed to disappear (Luskin and Shatz, 1985a) or to change in morphology (Parnavelas and Edmunds, 1983) during development. The early-generated layer I neurons are present in the adult ferret in relatively low numbers and are generated at the same time as the interstitial neurons in the white matter and deep layer VI cells. These early-generated layer I cells are interesting in that they are an exception to the pronounced inside-out pattern of neurogenesis observed in the ferret. The late-generated layer I neurons arise several weeks after those generated early and, in this regard, follow the inside-out pattern of neurogenesis. They are also found in the adult ferret in relatively low numbers. Thus, layer I contains at least 2 populations of nerve cells that have quite different developmental histories. These 2 populations also differ in other ways. The early-generated layer I neurons are CCK-immunoreactive, whereas the late-generated layer I nerve cells lack CCK immunoreactivity (Peduzzi and Hickey, 1985). Also, early-generated GABA-immunoreactive layer I neurons are, on average, larger than those generated later (Peduzzi, 1988).

Interstitial neurons generated between E20 and E29 are found in the white matter below layer VI. The neurogenesis of these interstitial neurons overlaps with the deep layer VI neurons and the early-generated layer I nerve cells. Interstitial nerve cells have been labeled in the adult ferret by injection of HRP into the cellular layers of the cortex, and some are also acetylcholinesterase positive (Rockland, 1985). As in the ferret, a substantial number of early-generated interstitial neurons continues to be found in the white matter in the adult monkey and human (Kostovic and Rakic, 1980). While some investigators believe that most interstitial cells disappear during development (Luskin and Shatz, 1985a; Wahle and Meyer, 1987), others believe that brain growth is responsible for their apparent decrease in number (Marin-Padilla, 1972; Rickmann et al., 1977). The number of interstitial neurons seen in the adult ferret cortex certainly appears to be less than that seen early in development. 
However, the quantification necessary to determine the relative contributions of cell death and the growth of the cortex to the apparent decrease in density of the interstitial cells during development has not been attempted.

\section{Differences between species}

Species variations have been noted in the precision with which the inside-out gradient is maintained throughout cortical neurogenesis. The timing of the inside-out radial pattern of neurogencsis in the ferret visual cortex most closely resembles that found in the monkey and the cat, while differing dramatically from that observed in rodents. Tritiated thymidine studies in the monkey (Rakic, 1974; Kostovic and Rakic, 1980) and the cat (Luskin and Shatz, 1985a, b) have shown that many days are required to produce all the neurons destined for a single layer of the adult visual cortex. The production of neurons for a given cortical layer in the ferret also takes place over a period of several days. In contrast, the production of neurons that make up a given cortical layer in rodents occurs over a 2-3 d period (Angevine and Sidman, 1961; Berry and Rogers, 1965; Shimada and Langman, 1970; Crossland and Uchwat, 1982).

Figure 3 shows that an injection on any given day labels visual cortical neurons that are scattered across 2 or more adjacent cortical layers in the ferret. Since all measurements are made at a single cortical position, this scatter cannot be attributed to tangential gradients of cortical nerve-cell production. While it is possible that the spatiotemporal gradient of cortical neurogenesis in the ferret is less precise than in the cat or monkey, a similar scatter in the radial distribution of cortical neurons generated on a single day is also present in the figures from the earlier studies in the monkey and cat. It is understandable that such scatter was not emphasized in those earlier studies since the inside-out gradients of cortical neurogenesis in the monkey and cat are, indeed, much more distinct than that reported for rodents. Furthermore, the expense and limited availability of timed-bred monkeys and cats undoubtedly restricted the number of developing animals available for analysis, so that interanimal variability could not be examined in detail. The smaller number of available subjects also limited the number of days sampled by ${ }^{3} \mathrm{H}$-thymidine injections. When fewer ages are examined, larger jumps in the radial positions of heavily labeled neurons are seen, even in our material. For example, if one compares only the radial strips for injection days E22, E29, E34, P1, P4, P10, and P14 in Figure 3, the radial gradient of neurogenesis in the ferret visual cortex also appears more distinct.

In many respects, the period of neuronal production in the ferret visual cortex is very similar to that of the cat (Luskin and Shatz, 1985b); however, the shorter gestational period of the ferret results in a significant period of postnatal cortical neurogenesis in this species. The striking similarity in the development of the cat and the ferret visual system is emphasized by the fact that the length of time from conception to eye opening is the same in the 2 species (Greiner and Weidman, 1981; Linden et al., 1981). Even though gestational periods differ substantially between the 2 species, there are only minor differences in the timing of neuronal cell birth for particular cortical layers. In fact, the only noticeable differences are a tendency for layers to be generated slightly earlier in the ferret than the cat and a slight increase in the length of time required to produce each layer in the ferret. Finally, 2 periods of layer I production were observed in the ferret. An early period of layer I nerve-cell production has also been described for the cat (Luskin and Shatz, 1985a, b), but a second period of layer I neuronal production at the end of cortical neurogenesis was not discussed.

\section{The importance of scatter}

The scatter in the final location of visual cortical neurons generated on a single day may represent more than imprecision in the process of neurogenesis. It may suggest that different subpopulations of cortical neurons vary in their development. For example, although GABA-immunoreactive neurons in the ferret visual cortex generally follow the same inside-out pattern of neurogenesis as nonimmunoreactive neurons, they are more broadly distributed across the radial dimension than other cortical neurons generated on the same day (Peduzzi, 1988). Therefore, at least some of the scatter in the radial distribution of neurons generated on a given day can be accounted for by the GABA-immunoreactive neurons. Clearly, the early-generated GABA-immunoreactive neurons located in layer I contribute substantially to the scatter seen early in neurogenesis. Almost all of these early-generated layer I nerve cells are also CCKimmunoreactive, while their late-generated counterparts, which follow the inside-out gradient, are not (Peduzzi and Hickey, 1985). Finally, Jensen and Altman (1982) find that X-irradiation late in the window of cortical neurogenesis causes the loss of callosally projecting neurons in the deeper layers, as well as in the supragranular layers. They point out that both the sequence of cortical neurogenesis and the pattern of callosal projections in the rat are less distinct than in monkeys or cats, and they suggest that the late-born population of infragranular neurons contributes to the callosal projection from these layers.

Our findings clearly show that scatter is present at the earliest stages of cortical development and suggest that differences in rates of migration may play a major role in causing the scatter. Our findings also indicate that scatter is greatest during periods of rapid neurogenesis. During such periods, the radial separation between the fastest and slowest migrating neurons generated at the same time is, in effect, magnified by the overall increase in the number of neurons being added to the cortical plate.

The mutual adhesion of cells within a given subpopulation during development may influence the amount of scatter exhibited by that subpopulation. Neurons that are mutually adhesive might be expected to exhibit minimal scatter, while those that exhibit little mutual adhesion may contribute substantially to the scatter observed in the developing and adult cortex. Alternatively, scatter could result from the aggregation of mutually adhesive cells generated at very different times during development, if such aggregates develop as neurons come into close approximation during migration. For either of these events to occur, subpopulations of neurons, varying in terms of their adhesive qualities, must exist during migration. Neuronal subpopulations may exist during migration as some cortical neurons already project to their targets during migration (Schwartz and Goldman-Rakic, 1986) and phenotypically distinct subpopulations of neural crest cells are found at early migratory stages (see Weston et al., 1988). Neuronal subpopulations may also exhibit differing levels of mutual adhesion as different fractions of developing chick retinal cells (enriched for particular cell types) vary dramatically with regard to the size of aggregates they form in vitro, suggesting differences in intrinsic intercellular adhesivity (Sheffield and Lynch, 1981). Recent in vitro studies have also shown that early-generated cortical neurons that share a birthdate are strongly adhesive to each other (Krushel and van der Kooy, 1988). The important role that cell or substrate 
adhesion molecules (CAMs or SAMs) play during development is also becoming increasingly obvious. For example, in the cerebellum, antibody to Ng-CAM or cytotactin differentially inhibited the migration of cells (Chuong et al., 1987).

Subpopulations that vary in their mutual adhesion might be expected to act differently when placed in an abnormal situation. Recent transplant studies of ferret visual cortical neurons (McConnell, 1988) find that when developing cortical cells normally destined for layers V and VI are transplanted into the cortex of a slightly more mature animal, i.e., one in which neurons destined for layer II-III are being generated, $43 \%$ of the transplanted cells that migrate end up in layer II-III and $38 \%$ of the transplanted cells that migrate end up in layers $\mathrm{V}$ and VI. Those neurons that migrated to layers V and VI may adhere to similar neurons and thereby reach their normal destination. This would also explain how different types of cells can become segregated within a lamina. For example, cells located in different parts of layer VI in the cat visual cortex send their projections to either the claustrum (lower half of layer VI), other visual cortical areas (upper half of layer VI), or the dLGN (central part of layer VI) (McCourt et al., 1986). Transplanted cells that migrated to layer II-III may exhibit little or no adhesion and migrate passively with the rest of the host neurons. Evidence that cells may migrate passively is provided by studies showing that latex beads move along the neural crest migratory pathway (Bronner-Fraser, 1982).

\section{References}

Angevine, J. B., and R. L. Sidman (1961) Autoradiographic study of cell migration during histogencsis of cerebral cortex in the mouse. Nature 192: 766-768.

Berry, M., and A. W. Rogers (1965) The migration of neuroblasts in the developing cerebral cortex. J. Anat. 99: 691-709.

Blenkinsopp, W. K. (1968) Duration of availability of tritiated thymidine following intraperitoneal injection. J. Cell Sci. 3: 89-93.

Bronner-Fraser, M. (1982) Distribution of latex beads and retinal pigment epithelial cells along the ventral neural crest pathway. Dev. Biol. 91: 50-63.

Chuong, C.-M., K. L. Crossin, and G. M. Edelman (1987) Sequential expression and differential function of multiple adhesion molecules during the formation of cerebellar cortical layers. J. Cell Biol. 104: 331-342.

Crossland, W. J., and C. J. Uchwat (1982) Neurogenesis in the central visual pathways of the golden hamster. Dev. Brain Res. 5: 99-103.

Greiner, J. V., and T. A. Weidman (1981) Histogenesis of the ferret retina. Exp. Eye Res. 33: 315-332.

Guillery, R. W., M. Ombrellaro, and A. L. La Mantia (1985) The organization of the lateral geniculate nucleus and of the geniculocortical pathway that develops without retinal afferents. Dev. Brain Res. 20: 221-233.

Hickey, T. L., D. R. Whikehart, C. A. Jackson, P. F. Hitchcock, and J. D. Peduzzi (1983) Tritiated thymidine experiments in the cat: A description of techniques and experiments to define the time-course of radioactive thymidine availability. J. Neurosci. Methods 8: 139147.

Jensen, K. F., and J. Altman (1982) The contribution of late-generated neurons to the callosal projection in the rat: A study with prenatal x-irradiation. J. Comp. Neurol. 209: 113-122.

Kostovic, I., and P. Rakic (1980) Cytology and time of origin of interstitial neurons in the white matter in infant and adult human and monkey telencephalon. J. Neurocytol. 9: 219-242.

Krushel, L. A., and D. van der Kooy (1988) Birthdate is more important than tissue type for the in vitro reassociation of early postmitotic cortical and striatal neurons. Soc. Neurosci. Abstr. 14: 91.

Law, M. I., and M. P. Stryker (1983) The projection of the visual world onto area 17 of the ferret. Invest. Ophthalmol. Vis. Sci. (Suppl.) 24: 227.

Law, M. I., K. R. Zahs, and M. P. Stryker (1988) Organization of primary visual cortex (area 17) in the ferret. J. Comp. Neurol. 278: 157-180.

Linden, D. C., R. W. Guillery, and J. Cucchiaro (1981) The dorsal lateral geniculate nucleus of the normal ferret and its postnatal development. J. Comp. Neurol. 203: 189-211.

Luskin, M. B., and C. J. Shatz (1985a) Studies of the earliest generated cells of the cat's visual cortex: Cogeneration of subplate and marginal zones. J. Neurosci. 5: 1062-1075.

Luskin, M. B., and C. J. Shatz (1985b) Neurogenesis of the cat's primary visual cortex. J. Comp. Neurol. 242: 611-631.

Marin-Padilla, M. (1972) Prenatal ontogenetic history of the principal neurons of the neocortex of the cat (Felis domestica). A Golgi study. II. Developmental differences and their significances. Z. Anat. Entwickl.-Gesch. 136: 125-142.

McConnell, S. K. (1988) Fates of visual cortical neurons in the ferret after isochronic and heterochronic transplantation. J. Neurosci. 8: 945-974.

McCourt, M. E., J. Boyapati, and G. H. Henry (1986) Layering in lamina 6 of cat striate cortex. Brain Res. 364: 181-185.

McSherry, G. M. (1984) Mapping of cortical histogenesis in the ferret. J. Embryol. Exp. Morphol. 81: 239-252.

McSherry, G. M., and I. H. M. Smart (1986) Cell production gradients in the developing ferret isocortex. J. Anat. 144: 1-14.

Otsuka, R., and R. Hassler (1962) Über Aufban und gliederung der corticalen sehsphäre bei der Katze. Arch. Psychiatr. Nervenkrankheiten 203: 212-234.

Parnavelas, J. G., and S. M. Edmunds (1983) Further evidence that Retzius-Cajal cells transform to nonpyramidal neurons in the developing rat visual cortex. J. Neurocytol. 12: 863-871.

Peduzzi, J. D. (1988) Genesis of GABA-immunoreactive neurons in the ferret visual cortex. J. Neurosci. 8: 920-931.

Peduzzi, J. D., and T. L. Hickey (1985) Peptide-like immunoreactive neurons in the visual cortex of the ferret. Invest. Ophthalmol. Vis. Sci. (Suppl.) 26: 326.

Rakic, P. (1974) Neurons in rhesus monkey visual cortex: Systematic relation between time of origin and eventual disposition. Science 183: $425-427$.

Rakic, P. (1976) Differences in the time of origin and in eventual distribution of neurons in areas 17 and 18 of visual cortex in rhesus monkey. Exp. Brain Res. (Suppl.) 1: 244-248.

Rakic, P. (1977) Prenatal development of the visual system in rhesus monkey. Phil. Trans. R. Soc. London [Biol.] 278: 245-260.

Rickmann, M., B. M. Chronwall, and J. R. Wolff (1977) On the development of non-pyramidal neurons and axons outside the cortical plate: The early marginal zone as a pallial anlage. Anat. Embryol. 151: 285-307.

Rockland, K. S. (1985) Anatomical organization of primary visual cortex (area 17) in the ferret. J. Comp. Neurol. 241: 225-236.

Schwartz, M. L., and P. S. Goldman-Rakic (1986) Some callosal neurons of the fetal monkey frontal cortex have axons in the contralateral hemisphere prior to the completion of migration. Soc. Neurosci. Abstr. 12: 1211 .

Sheffield, J. B., and M. Lynch (1981) Cell surface differentiation in the embryonic chick retina. In Ocular Size and Shape, S. R. Hilfer and J. B. Sheffield, eds., pp. 99-122, Springer-Verlag, New York.

Shimada, M., and J. Langman (1970) Cell proliferation, migration and differentiation in the cerebral cortex of the golden hamster. J. Comp. Neurol. 139: 227-244.

Sidman, R. L., P. A. Mottla, and N. Feder (1961) Improved polyester wax embedding for histology. Stain Technol. 36: 279-284.

Wahle, P., and G. Meyer (1987) Morphology and quantitative changes of transient NPY-ir neuronal populations during early postnatal development of the cat visual cortex. J. Comp. Neurol. 261: 165-192.

Walsh, C., and E. H. Polley (1985) The topography of ganglion cell production in the cat's retina. J. Neurosci. 5: 741-750.

Weston, J. A., K. S. Vogel, and M. F. Marusich (1988) Identification and fate of neural crest cell subpopulations in early embryonic development. In From Message to Mind, S. S. Easter, K. F. Barald, and B. M. Carlson, eds., pp. 224-237, Sinauer, Sunderland, MA. 